\title{
CONSTRUIR SENTIDOS EN EL UMBRAL: EL FORMATO TEXTO-FOTO-AMALGAMA DE MARIO BELLATIN ${ }^{1}$
}

\author{
GIANNA SCHMITTER \\ Université Sorbonne Nouvelle Paris III / \\ Universidad Nacional de La Plata \\ gianna-schmitter@hotmail.de
}

RESUMEN: Se trata de indagar en la relación entre texto y foto -con las palabras de Mario Bellatin el formato texto-foto-amalgama- del ciclo intermedial publicado entre 2008 y 2009 con los títulos "Todos saben que el arroz que cocinamos está muerto. Pequeña autobiografía ilustrada", Biografía ilustrada de Mishima, Las dos Fridas, Los fantasmas del masajista, así como El libro uruguayo de los muertos (2012). Estas obras mantienen importantes interconexiones: el artículo propone reflexionar sobre las migraciones y recuperación del material fotográfico entre estas publicaciones. Se trabaja a partir de la teoría de la intermedialidad para analizar cómo se construyen y cambian sentidos, lecturas, percepciones y experiencias literarias. En una primera parte se examina el formato texto-fotoamalgama, y en una segunda las migraciones.

PALABRAS CLAVE: Mario Bellatin; literatura y fotografía; intermedialidad; pie de foto

ABSTRACT: This article analyses the relationship between text and photo -which Mario Bellatin calls the texto-foto-amalgama-format- in the light of the intermedial cyclus that was published between 2008 and 2009 and that includes the following titles: "Todos saben que el arroz que cocinamos está muerto. Pequeña

1 Agradecemos a Mario Bellatin por autorizar la reproducción de sus imágenes en el presente artículo. 
autobiografía ilustrada", Biografía ilustrada de Mishima, Las dos Fridas, Los fantasmas del masajista, and El libro uruguayo de los muertos (2012). Amid the substantial interconnections of these publications, this article reflects the migration and reuse of the photographic material. Applying intermediality theories, we analyse how meaning, experience and literary perceptions are constructed and changed. The first part of this article examines the texto-foto-amalgama-format, and the second focuses on the migrations.

KeYWords: Mario Bellatin; Literature and Photography; Intermediality; Photolegend

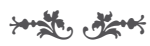

El autor peruano-mexicano Mario Bellatin indica en El libro uruguayo de los muertos que "[a]ctualmente estoy construyendo una serie de texto-imagen, como los Ilamo. Algunos ya salieron incluso publicados. En la revista Letras libres de agosto se encuentra el primero. No puede aparecer el uno sin el otro, es decir la imagen sin el texto y viceversa. Bajo ciertas características además" (2012a: 11-12). Es un libro narrativo y meta-narrativo que, aunque reflexione acerca de la relación entre texto y fotografía, no incluye ninguna foto. ${ }^{2}$ Sin embargo, parece encerrar o aportar claves de lectura para su ciclo intermedial elaborado a través de textos e imágenes -el formato texto-foto amalgama (Bellatin 2012a: 124)- publicado entre 2008 y 2009.

La primera publicación de la serie texto-imagen es "Todos saben que el arroz que cocinamos está muerto. Pequeña autobiografía ilustrada" (Bellatin 2008c), mencionada en la cita que abre este trabajo. Este texto se vuelve a publicar sometido a una ligera reescritura en el libro Biografía ilustrada de Mishima (2009a), junto con dos de las cuatro fotografías originales. Biografía ilustrada... se conecta a su vez con Las dos Fridas (2008b) -y este texto será retomado casi enteramente en El libro uruguayo (2012: 97-120)- y Los fantasmas del masajista (2009b), que Alfaguara publicó bajo el título La clase muerta: dos textos (2011, 2013, incluyendo la Biografía ilustrada de Mishima). Estas importantes interconexiones se inscriben, según Cote Botero, en un "sistema Bellatin" (2014: 9). Afirma que "[d]esde su primera novela constituye una constante de escritura de Mario Bellatin la reincorporación de personajes, episodios aislados o fragmentos de libros anteriores; repeticiones que provocan al lector la sensación de un constante déjà vu" (2014: 120). Dicho déjà vu se vuelve literal en cuanto a las fotografías que migran en el sistema Bellatin, sobre las cuales centraremos la reflexión.

\footnotetext{
2 No obstante, el lector puede escribir a la Editorial Sexto Piso y pedir El libro-fantasma de El libro uruguayo de los muertos, un PDF de 32 páginas con párrafos migrados del Libro uruguayo... y 14 fotos. En la última página del PDF afirma el autor: "Pienso como libros-fantasmas aquellos que aparecen en forma paralela a la edición original. Bastante simples. Sin tapas, engrapados, en cuya portada contengan solo la información del libro original como una manera de vincular las dos instancias: la del libro publicado y la de su presencia inmaterial. Sería la primera editorial, creo, que en lugar de aprisionar la información, convirtiéndola en un coto cerrado, serviría como verdadero vehículo de aceleración y distribución real de las ideas" (Bellatin 2012b).
} 
Las fotografías se ubican en el umbral de los textos -tanto material como espacialmente-, abriendo, complementando, o desestabilizando la lectura gracias a los pies de foto. Estos funcionan como un puente entre texto lingüístico y foto o texto-imagen, lo que requiere, entre otros, un cuestionamiento de los significados de leer en cuanto construir sentido(s). Si sumamos a las migraciones del material fotográfico -que atañen a la construcción de sentido- el metadiscurso que se halla en El libro uruguayo de los muertos, se crea una red intermedial y textual más allá de la unidad-libro que desestabiliza el significado hasta tal punto que ya no concuerda con lo que inicialmente parecía significar. Así habría que preguntarse si se construyen sentidos y dónde; cómo cambia la lectura con las migraciones, y por ende qué significa esto para el texto, las fotos, la relación y la construcción intermedial. Intentaremos responder a estos planteamientos investigando primero el formato texto-foto amalgama tal como fue propuesto por Bellatin, y luego el sistema de significación inestable generado por las migraciones.

\section{Formato TEXTO-FOto-AMALgama}

El formato texto-foto-amalgama significa, en palabras del autor, "que no puede existir una sin la otra. La imagen sin el texto y viceversa" (2012a: 124). Sin embargo, encontramos varias posibilidades de combinación:

(1) las fotos pueden o no tener pie de foto;

(2) las fotos se pueden encontrar apartadas en un dossier fotográfico;

(3) las fotos pueden coexistir al lado del texto.

Cada combinación conlleva otra dinámica para la relación intermedial. Nos concentramos aquí en las fotografías que tienen pie de foto y por esto una carga ilustrativa y asociativa más guiada por la palabra. Sin embargo, la obra del autor consta de más libros y textos que los acá analizados en los que también introduce fotos, sacadas por él o por fotógrafos. Por ejemplo: Shiki Nagaoka: una nariz de ficción (2001 fotos: X. Berecochea), Perros héroes: tratado sobre el futuro de América Latina visto a través de un hombre inmóvil y sus treinta Pastor Belga Malinois (2003), Jacobo el mutante (2006, fotos: X. Berecochea), y Demerol: sin fecha de caducidad (2008a, fotos: G. Iturbide). Este último libro forma parte del círculo de interconexiones aquí analizadas, ya que Bellatin inscribe parte de su bio- y bibliografía en la de Frida Kahlo. No lo incluimos en este trabajo porque M. Bellatin no es autor de las fotos y, por ello, la estética de las fotos se aleja de las coordinadas consideradas en este ensayo; asimismo este libro no ofrece un trabajo con pies de foto.

\subsection{Breve presentación del corpus}

El texto "Todos saben que el arroz que cocinamos está muerto. Pequeña autobiografía ilustrada" se publicó en una sección de la revista Letras Libres. El texto apenas cubre dos páginas y se podría clasificar como una acumulación de anécdotas, acompañado por cuatro fotos que ocupan otra página más: 
son, entonces, apartadas del texto lingüístico, es decir que se trata de una postilustración que sin embargo se relaciona con el texto por los pies de foto.

Los fragmentos de este texto se reciclan en la Biografía ilustrada de Mishima, con un cambio del enfoque del narrador: de uno autodiegético a uno homodiegético (Genette 1972), que relata una conferencia dictada por un universitario japonés sobre la vida post-decapitación del autor japonés Mishima. El libro hace honra a su título: contamos con 41 "ilustraciones" por 26 páginas de texto en el caso de la reedición de Alfaguara, y 50 "ilustraciones" en la edición inicial de Entropía. Las fotos se presentan igualmente aquí en un dossier fotográfico apartado.

En Los fantasmas del masajista se narra la muerte de la madre de João, masajista favorito del narrador. La madre, famosa declamadora en la radio brasileña, fue invitada, después del auge de su carrera, a recitar fuera de Brasil para declamar la canción "Construcciones" de Chico Buarque, canción de la cual no llega a entender todos los matices y que pondrá un punto final a su carrera. El libro consta de 14 páginas de texto con 22 fotos (edición Alfaguara), también reunidos en un dossier fotográfico.

Las dos Fridas - libro por encargo sobre Frida Kahlo, donde Bellatin documenta su viaje para encontrar una mujer parecida a Frida Kahlo, que trabaja en el mercado de un pequeño pueblo mexicano- presenta 43 páginas de texto acompañadas siempre de una foto, más 20 fotos donde se recortó un detalle, o sea un total de 63 fotos. Cada foto tiene subtítulo y dada la cohabitación de texto y foto en el mismo espacio limitado de la página, la forma de organización del soporte ofrece más variedad que en el caso del dossier: encontramos fotos alineadas al borde de la página alrededor de las cuales el texto se construye; páginas donde la foto está en el medio, lo que conlleva la fragmentación del texto; fotos que ocupan la mitad o más de la página y el texto llena el espacio restante.

Así tenemos dos dinámicas. Primero, la foto entra en una suerte de competencia ${ }^{3}$ espacial con el texto, competencia que no se da en el caso del dossier apartado, ya que cada foto goza ahí de una página: es como un cuadro colgado en un muro, con título. El lector no se preguntará por el orden de "lectura" (¿primero mirar la foto, o leer el texto?): su mente está cargada con la información que acaba de leer, se puede detener de otra manera en las imágenes. De este modo, lo importante es la relación que se establece desde un punto de vista semiótico, el nuevo espacio visual-escritural que se crea en el umbral y el cual apela a la competencia del lector. El segundo aspecto en el caso de Las dos Fridas es que se suelen ilustrar en las fotografías detalles omitidos, o solo evocados en el texto. De esta manera la imagen se apropia de una de las clásicas funciones del texto: la descripción. ${ }^{4} \mathrm{Al}$ mismo tiempo se imbrican texto lingüístico e imagen,

\footnotetext{
${ }^{3}$ Gersende Camenen (2013) destaca que puede haber una relación de competencia o de complementariedad.

${ }^{4}$ M. Covindassamy (2014) resalta en cuanto a la obra de W. G. Sebald -quien por cierto no trabaja con la misma estética de M. Bellatin, sin embargo la reflexión de Covindassamy nos parece interesante a nivel de las posibilidades propias de cada medio- que el contacto entre texto e imagen conlleva una puesta en tela de juicio de las posibilidades e idiosincrasias del medio textual, sobre todo lo referible a la descripción.
} 
ya que los dos medios sirven para contar el viaje y la búsqueda desde diferentes enfoques: Las dos Fridas se construye así como una especie de road movie. ${ }^{5}$

\title{
1.2. Las fotos
}

Las fotos son tomadas con cámaras estenopeicas ${ }^{6}$, son artefactos manuales, donde el proceso cobra importancia:

\begin{abstract}
Pero nada que esté dentro del mundo virtual debe servirme para llevar a cabo mi proyecto. Tal como pretendo hacer con la escritura, lo primitivo debe tener una presencia real. No lo primitivo visto como una contraposición con lo contemporáneo, sino por el trabajo manual, real, que supone el proceso fotográfi$\mathrm{Co}$, desde equipar la cámara con un rollo hasta tener la copia revelada después de un trabajo casi alquímico. (Bellatin 2012a: 148)
\end{abstract}

Los resultados son instalados en las páginas donde, en los dossiers al final del texto, son una recapitulación del texto anteriormente leído, un leer-doble con y a partir de imágenes que influye en la narración. La estética obtenida son fotos jugando con lo desenfocado, lo borroso, en blanco y negro o colores lavados, que justamente hacen evidente los procedimientos y contextos de composición. Desde el lado del sentido, las fotos evocan algo fantasmagórico: se trata de "unas fotos extrañas, como enmarcadas en su propio tiempo y espacio. [...] En la mayoría de las fotos conseguidas con esa técnica se ve retratado algo así como el infinito" (Bellatin 2012a: 54). Incluso se podría hablar de una estética translúcida, no solamente por emplear materias translúcidas ${ }^{7}$ para obtener mayores disyunciones, sino también porque el texto se trasluce a través de la foto, y la foto a través del texto: "Creo que mi pretensión con las fotos es tener únicamente un registro que, de alguna manera, sirva como un esqueleto visible de la escritura" (Bellatin 2012a: 37).

Dicha estética se opone a una búsqueda realista: las fotos, desprovistas de un potencial mimético por lo borroso, sugieren algo. Como lo señala Diana Palaversich: "Bellatin emplea el discurso fotográfico de una manera posmoderna:

\footnotetext{
${ }^{5}$ Escribe el autor en El libro uruguayo...: "Decidí también ilustrar la travesía. Quise hacer un registro gráfico desde el momento en el que abandonaba mi casa hasta el instante en el que encontrara a esta mítica Frida Kahlo. Deseé realizar el registro por medio de la fotografía. Fue precisamente ese el momento en que decidí buscar la cámara de mi infancia" (2012: 102).

6 Mario Bellatin nombra diferentes cámaras en varias de sus obras, como por ejemplo: "Llevé conmigo mi cámara estenopeica, es decir, un instrumento de madera que como sabes en lugar de lente lleva una pequeña platina agujereada con la punta de un alfiler" (2012a: 97).

${ }^{7}$ La estética translúcida se muestra en varios niveles. Materialmente se revela lo translúcido como objeto fotografiado en superposiciones de papeles con ideogramas (cf. Shiki Nagaoka...), en fotos que reproducen agua (cf. Shiki Nagaoka..., Biografía ilustrada..., Los fantasmas...), en vidrios de ventanas (cf. Shiki Nagaoka..., Biografía ilustrada..., Los fantasmas..., Las dos Fridas) u otros elementos que dejan traspasar la luz (cf. Biografía ilustrada...). Más allá de esto el autor interpone materiales translúcidos ante el objeto fotografiado y la lente con el fin de hacer hincapié en la materia para que haga brotar una forma de experiencia de la mirada (cf. Biografía ilustrada...). Finalmente, la mayoría de las fotos tomadas por Mario Bellatin trabajan con lo borroso y lo movido (para profundizar, cf. Schmitter, 2016).
} 
presenta la imagen no como una prueba por excelencia de la referencialidad y la (re)producción de significado, sino más bien como sitio en el cual lo real está siempre ausente" (2003: 29). Las fotos inducen, o potencian así una atmósfera, ya presente en los textos, una atmósfera que cobra visualidad, y refuerza el universo de los libros:

Es impresionante cómo, de alguna manera, se reproduce en las imágenes el universo de los libros. Me sucedió con una serie de fotos hechas el otro día, lo que nunca me ha pasado frente a la palabra escrita, y menos con algo que yo haya hecho: me llegaron directamente al corazón y me produjeron una tristeza profunda. (Bellatin 2012a: 121)

Las fotos tienen por ende un potencial espectacular - pueden conmover, son ilustrativas, guían la imaginación del lector- pero no tienen potencial propiamente narrativo, si definimos lo narrativo para una sola imagen, con Klaus Speidel (2013), como la necesidad de presentar un planteamiento, un nudo y un desenlace, es decir una dimensión cronológica. ${ }^{8}$ Así, las fotografías que estamos considerando no contienen narración. ${ }^{9}$ Muestran ${ }^{10}$ algo y, a veces, justamente por la estética translúcida, no se sabe bien qué muestran. Hacen hincapié en un detalle del texto que muchas veces no cobraba importancia en el texto lingüístico, lo que abre la historia: el sentido y la narración se construyen gracias a los pies de foto, es decir gracias a la intermedialidad que siempre es una constitución de sentido y posiblemente también una transfiguración de sentido y de percepción. Es decir que la mayoría de las fotos no constituye una narración per se si se piensa en una definición restringida de narración, salvo cuando las articula el lector/espectador. El pie de foto añade información que puede ayudar u obstaculizar, y esta red opera abriendo la historia o la interpretación del textofoto-amalgama.

8 Estamos trabajando con una definición restringida de narración que se limita a la consideración de la imagen de por sí. Otro nivel de reflexión sería la consideración de una serie de imágenes, o bien la toma en cuenta de la situación de producción de la fotografía.

9 De esta manera, nuestra lectura se opone a la de Iván Salinas Escobar (2006) para quien las imágenes narran.

10 Para la idea de que las fotos muestran algo, cf. Mariniello, que subraya el carácter deíctico de la fotografía, apoyándose en Bazin: "Hay una diferencia entre la presencia indexical de la fotografía y el contenido de la foto que el lenguaje puede tratar. La deixis, constitutiva del acto de tomar una foto, escapa al lenguaje, o, más bien, identifica sus límites así como los límites de un sujeto que trata de captar el mundo y que se desbarata en el proceso" (2009: 73). Y más lejos sigue: "Las imágenes analógicas y numéricas nos dan 'un mundo que ha sido sometido al trabajo del lenguaje y que ha salido de él intacto' (Godzich, The Language Market, 20); esta poderosa y sugerente frase evoca la crisis de la literacy moderna y desafía a los investigadores a trabajar en esta dirección. Lo que está en juego aquí no es la oposición binaria entre la época de la literacy y la época del audiovisual, sino el reconocimiento de la insuficiencia de la literacy moderna (textual) frente a las diferentes prácticas sociales de la visualidad humana que han sido domesticadas, ignoradas o hechas de lado en la cultura de la literacy y que se imponen a través de los intercambios cada vez más frecuentes e intensos y el rápido desarrollo de los medios audiovisuales, especialmente el cine y la televisión" (2009: 74-75). El uso de la fotografía -o actualmente el dibujo- en la obra de Mario Bellatin se afronta así a la crisis de la "literacy moderna": utilizando estrategias inter y transmediales, se busca seguir expresándose, (con)mover desde otros lugares. 


\subsection{Combinación de medios}

El formato texto-foto-amalgama se puede clasificar, dentro de la investigación intermedial ${ }^{11}$ como combinación de medios. ${ }^{12}$ Esto es, según Irina $\mathrm{O}$. Rajewsky, una interacción entre dos o más medios que puede llegar hasta una fusión:

La calidad de lo intermedial afecta en el caso de la combinación de medios la constelación del producto medial, es decir la combinación, mejor dicho el resultado de la combinación de por lo menos dos medios que están percibidos convencionalmente como distintos, y que están presentes en su materialidad y aportando a la constitución (de significado) del producto entero con su manera propia, especificada por el medio. La intermedialidad se presenta así en este caso como un concepto comunicativo-semiótico que se basa en -esto es decisivo- la adición de por lo menos dos sistemas mediales convencionalmente percibidos como distintos. (Rajewsky 2002: 15)

Las formas de combinación posibles son la contigüidad, la coexistencia o la interacción. La interacción está dada, en nuestro caso, por los pies de foto: efectivamente, en la gran mayoría de las veces, no se puede deducir a partir de la foto con qué lugar en el texto hay que asociar la imagen. Entonces, los pies de foto son una suerte de modo de empleo de la foto, una guía de lectura que indica el contexto. Como lo subraya Werner Wolf -y volvemos con esto a la idea de que no toda imagen narra- la imagen como ilustración del texto no representa una historia; solamente indica historias: "aunque la referencia intermedial contribuye sobremanera a que se vuelva al mismo tiempo fuertemente inductora para la historia" (Wolf 2002: 75). ${ }^{14}$

\footnotetext{
11 Utilizamos el término intermedialidad para referirnos a la combinación de literatura con otro medio que no sea textual (caso que abarca la intertextualidad), es decir la combinación de la literatura con el arte gráfico (pintura, fotografía...), el cine, la música, el ciberespacio... Se puede encontrar una intermedialidad in praesentia (reproducción, o bajo otra forma concreta, interactiva, como un video en la red) e in absentia (evocación, tematización, etc.). Esto conlleva una construcción de sentido, otros regímenes de estética y de comunicación. Para un desarrollo pormenorizado de estos conceptos de la teoría de la intermedialidad ver: Wolf (2006, 2011), Rajewsky (2002), Böhn (2003), A. Nünning y V. Nünning (2002).

12 Por razones de espacio se analizará el concepto foto-texto-amalgama solamente a partir de las teorías de la intermedialidad, dejando de lado conceptos como "imagetext" de W. J. T. Mitchell, elaborado entre otros en sus libros Iconology: Images, Text, Ideology (1986) y Picture Theory, Essays on Verbal and Visual Representation (1994). Aunque Mitchell fue un pionero en pensar la relación entre texto e imagen (imagetext, image/text, image-text), y en subrayar que todos los medios son medios mixtos, nos parece por un lado que su punto de vista se vuelca más sobre cuestiones políticas, ideológicas y pedagógicas (1994: 88). Por otro lado no logró ofrecer una construcción teórica acabada, como él mismo admite (1994: 107, 417, 418), sino que "[the image/text] might be described, not as a concept, but as a theoretical figure rather like Derrida's différance, a site o dialectical tensión, slippage, and trasnformation" (1994: 106).

${ }^{13}$ En todos los casos de las teorías de intermedialidad alemanas la traducción siempre es nuestra.

14 En cuanto a la imagen que induce la historia, o bien la escritura, afirma Bellatin en unos fragmentos de El libro uruguayo..., que parece ser constituido por partes extraídas de emails enviados a un amigo: "Ahora te quiero detallar el momento actual [...]. Me encuentro delante de decenas
} 
La noción de historia nos lleva a abrir otro campo de reflexión. Si hemos intentado más arriba indicar de qué tratan las obras de este ciclo de Bellatin, para algunas de ellas parece más difícil ofrecer un resumen que para otras. Diana Palaversich afirma incluso que

... [s] us novelas [...] son prácticamente imposibles de contar puesto que en ellas abundan las rupturas narrativas, cuyo sentido es siempre desplazado (always already deferred). Lo que importa no es tanto lo que ocurre sino cómo se presenta y manipula la materia narrada que nunca lleva a un 'desciframiento' final. (Palaversich 2003: 25)

¿Cómo entonces hablar de historia, o de narración? Los fragmentos con los cuales se construye el texto se pueden entender como diversos argumentos, de los que no necesariamente todos desembocan en la construcción de sentido. Wolf sostiene que narrar sería

... la representación de por lo menos rudimentos de un mundo vivible e imaginable, la cual se centra en al menos dos tramas o condiciones diferentes de las mismas figuras antropomórficas y, más que por mera cronología, estas están potencial pero no necesariamente en relación significativa. (Wolf 2002: 51)

Esta definición de narración -minimalista y por ello aplicable a varios medios, asimismo como a las diversas relaciones intermediales- ofrece la posibilidad de entender la narratividad como fenómeno graduable: según Wolf, se constituye de narremas ${ }^{15}$ (2002: 38) que se agrupan según una lógica cualitativa, sintáctica y de contenido (2002: 44 ss.). A continuación veremos cómo este término puede permitir hablar de narración en el caso de nuestro corpus, donde la narración se halla tanto en el texto verbal habitual en el formato-soporte de libro impreso, como en cierto punto en la interacción entre fotografía, subtítulo y texto generada por Bellatin a partir de su concepto texto-foto-amalgama. La confrontación de los dos medios hace surgir sentido(s) en el umbral: gracias a los enlaces tejidos entre la historia, el subtítulo y la foto se convocan sentidos y experiencias de significación diversas.

\section{EL SISTEMA UNIDAD DE SENTIDO RECICLADA: MIGRACIONES}

Los narremas constituyen, a su vez, unidades más o menos narrativas: entendemos estas unidades en el caso de Bellatin como un conjunto de sentidos hechos de elementos variables en su forma. Se puede tratar tanto de fragmentos textuales, como de foto-texto-amalgama. Estas unidades migran en la obra de Mario Bellatin. El interés de hablar de unidades reside en el hecho de poder

de fotografías tomadas con una cámara de plástico. Al centro de la mesa está la computadora [...]. Pretendo, mirando las imágenes, inducir la escritura. Armar primero una suerte de itinerario. A la manera de un texto de viaje ..." (2012a: 147-148, el subrayado es nuestro).

15 Narremas son "factores de narratividad; marcas, 'formas huecas' en cuanto al contenido y 'reglas sintácticas' de lo narrativo" (Wolf 2002: 42). 
explicar las migraciones: encontramos fotos que están recontextualizadas y entonces cargadas con otro sentido; hallamos la misma unidad textual asociada a otra foto; en re-publicaciones hay recortes de fotos o eliminaciones de fotos (de unidades asociativas suprimidas); tanto como cambios y reescrituras a nivel de las unidades-textuales. El sistema de auto-alimentación que se crea a partir de la recuperación, del reciclaje, o de la lógica del copy and paste ${ }^{16}$ corresponde a una lógica de hiperenlaces ${ }^{17}$ y se transforma así en una de las poéticas principales del autor. Cote Botero divide este sistema en tres clases:

En la obra de Mario Bellatin hay un sistema de recurrencias [...] que en términos muy generales podría dividirse en: circuito de formas auto-referenciales, una comunidad de temas que suponen la construcción de un sistema de insistencias y el de la copia, entendida ésta, no como imitación sino como re-creación de un segmento. (Botero 2014: 22)

Veremos a continuación que el recurso a la intermedialidad se sabe perfectamente adaptar a este sistema, ya que se trata en el caso de las fotos de unidades que se pueden desplazar como un fragmento, dado que están materialmente presentes en el soporte-libro. Las ocurrencias de migraciones que encontramos en nuestro corpus son:

1. Misma foto, otro motivo:

a. "Habitación con ventana" (vid. 2.1.).

b. "Silueta junto a vidriera": La foto muestra una figura sentada en una suerte de hall, junto a una vidriera, fotografiada a contraluz. En Las dos Fridas lleva el pie de foto: "Mujeres que trataban de persuadir a los foráneos que se acercaran a Frida Kahlo" (2008b: 38) y en la Biografía ilustrada de Mishima el pie de foto: "Rincón del adoratorio sintoísta al lado de la granja del tío de Mishima" (2009a: foto n³7).

c. "Mortaja": es una foto borrosa de una supuesta mortaja. El pie de foto en Las dos Fridas indica "Mortaja diseñada para el cuerpo de Frida Kahlo" (2008b: 40) y en el caso de Los fantasmas... "Mortaja que las declamadoras ofrecieron a João" (2009b: foto $\mathrm{n}^{0} 13$ ).

2. Mismas fotos, mismos motivos:

a. "Hermanas de la madre" (vid. 2.3.).

b. "El cementerio": Se trata de una migración entre "Todos saben que..." donde lleva el pie de foto: "Cementerio donde acostumbro alimentarme" (Bellatin 2008c: 63) y Biografía ilustrada... con el pie de foto:

\footnotetext{
16 En 2008 Daniel Link publicó una nota de Mario Bellatin, en la que precisa su técnica de copypaste, en su blog Linkillo, cosas mías: "*Querido L: te quería informar que ayer en ADN salió una nota mía sobre kawabata...envié la nota con un pie de página donde decía que había sido hecha con la técnica de copypaste (copyright 2008), pie que no apareció lamentablemente... es que para responderme una serie de preguntas hice ese texto juntando una serie de fragmentos que distintos críticos han hecho sobre mis libros... cambié la palabra bellatin y le puse kawabata, cambié el nombre de algunas obras y yastá... salió un artículo estupendo sobre kawabata, impecable en su verosimilitud y certeza cosa que, entre otras cosas, nos demuestra que sólo hay una palabra, que siempre se puede hablar sólo de lo mismo.... [...] Mario**" (Bellatin y Link 2008).
}

17 Ver Craig Epplin (2015) y Adam Morris (2012). 
"Cementerio donde Mishima acostumbra alimentarse" (Bellatin 2013: foto $n^{\circ 16)}$.

3. Otra foto, mismo motivo:

a. "La cabaña" (vid. 2.2.).

4. Conexiones (variaciones con o sin foto, metacomentarios -hay más ocurrencias que las tres mencionadas-):

a. "La vasija de arroz": La foto retrata una olla grande y se publica en Biografía ilustrada con el pie de foto: "Vasija en la que Mishima acostumbra inspirarse para escribir su inacabado libro sobre una mujer que cocina arroz." (2013: foto $\left.n^{\circ} 10\right)$. Encontramos el mismo motivo del texto central en "Todos saben que..." y metacomentarios en El libro uruguayo... (2012a: 10, 56).

b. "Los converse de Frida": En la foto se ve un zapato Converse, con imágenes de Frida Kahlo. Se publicó en Las dos Fridas. Dice el pie de foto: "Tenis con la imagen de Frida Kahlo, de cuya venta se reserva un porcentaje para ayudar a mujeres de comunidades indígenas" (2008b: 43), sucitando a su vez metacomentarios en El libro uruguayo... (2012a: 9, 146).

c. "Cabaña de la que se huyó": La foto muestra una mesa de madera blanca. El pie de foto informa que se trataría de la "Mesa de madera sobre la que Mishima dejó olvidados sus textos" (2013: foto $\left.n^{\circ} 40\right)$. En el Libro uruguayo... el narrador retoma y se apropia de esta anécdota (2012a: 32).

\subsection{MisMA FOTO, OTRO MOTIVO}

El caso que focalizaremos se podría denominar "habitación con ventana" (fig. 1-3) y se encuentra tanto en Las dos Fridas como en Los fantasmas... En las figuras 1-3 de la tabla 1 se trata de la misma unidad-foto-aunque se puedan notar diferencias en las publicaciones (recorte, otra saturación, otro papel de impresión, etc.). La fig. 1 se publicó en Las dos Fridas, junto a una descripción de la habitación de Frida Kahlo. La ventana no se describe en el texto lingüístico, así como los detalles mencionados no se pueden ver en la foto. Lo único que relaciona la foto con el texto es el pie de foto. Cuando este cambia, cambia también la experiencia de significación. No cambia el espacio asociado, pero cambia el contexto y la dueña: de Frida Kahlo pasa a la madre de João. Tampoco aquí se habla de la ventana -objeto dominante en la foto-, pero el bulto en el margen inferior podría concordar con "la cama [que] estaba sin hacer" (Bellatin 2013: 597). 


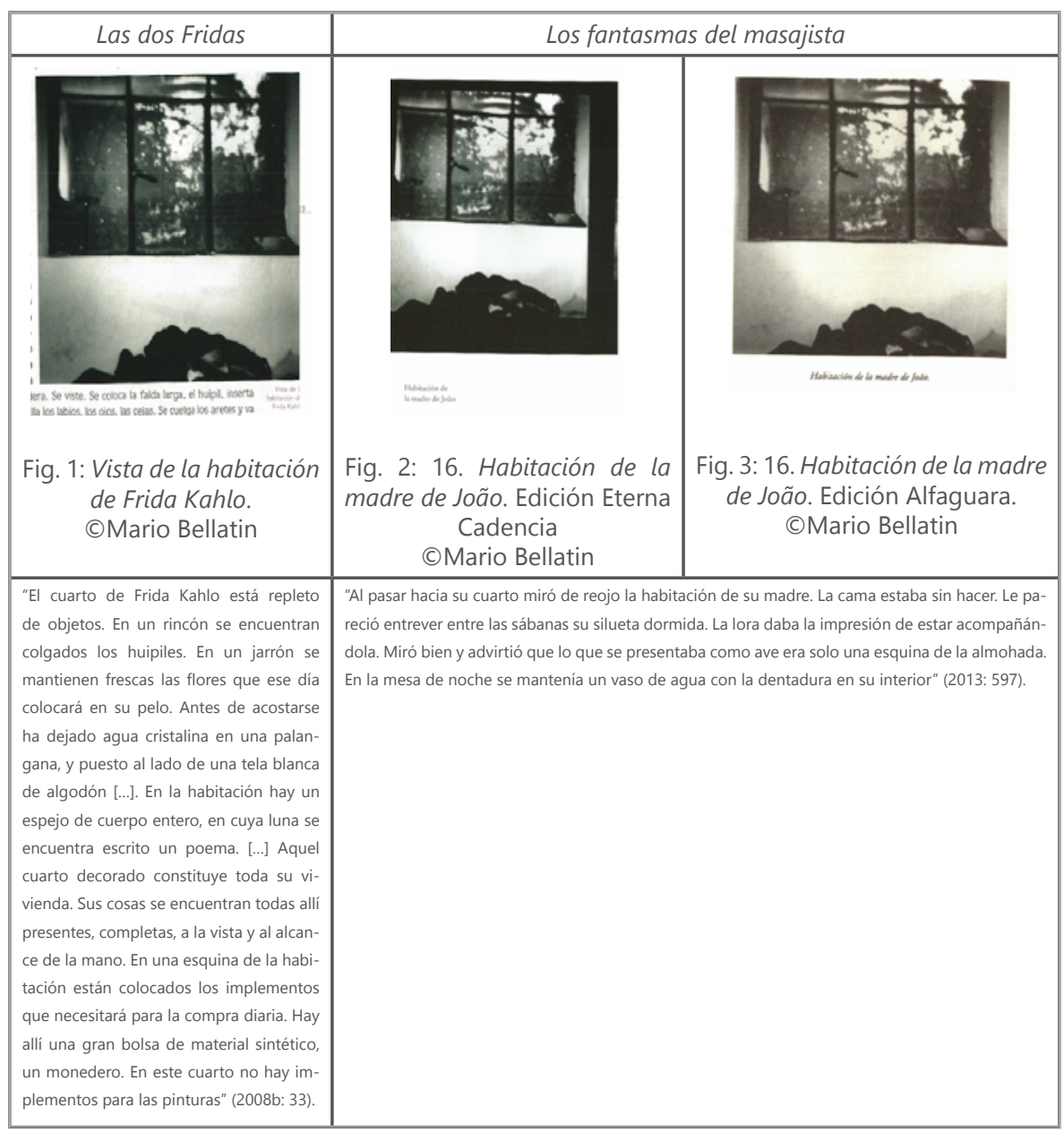

Tabla 1: Comparación de "habitación con ventana"

La mudez de la foto permite colocarla en otros contextos, volver a utilizarla y cargarla con otro significado. Propone más detalles, o solamente una atmósfera, pero guía la lectura y la imaginación: la visualidad que cobra la lectura del texto puede, incluso, ser contraproducente para la imaginación propia del lector, o al contrario sugerente cuando las fotos se vuelven más borrosas y dejan así más espacio para rellenar los "blancos" creados por la estética. La reutilización de la foto implica su independización respecto al referente, y al mismo tiempo se presta al juego, a la trampa. Bellatin insiste en varias entrevistas en la idea de construir un universo paralelo para leer doblemente, como lo afirma en una entrevista con Fermín Rodríguez: "Uno está esperando una forma determinada para un tema, pero si el tema está y la forma es totalmente inesperada, se crea esa cosa que hace que leas doblemente" (Rodríguez 2006: 68). Se trata 
de construir un universo paralelo: apelando a la visualidad, se busca apoyarse en algo, sabiendo que es un simulacro, un juego. Un juego donde se emplea lo translúcido, las trampas, la reutilización y el cambio de significado.

\subsection{Otra foto, misma unidad-texto}

La unidad-texto que acompaña estas dos fotos (vid. Tabla 2), publicada en "Todos saben que..." y Biografía ilustrada, es -si pensamos con el modelo de la unidad o, con Margo Glantz, la unidad como tema musical- la misma unidad variada:

Estamos ante un encadenamiento sucesivo de textualidades cuyo signo remitiría a un procedimiento que en el campo de la música se conoce como el tema y sus variaciones, en donde se trabaja sobre un tema dado, reproducido y traspuesto con aditamentos que suelen transformar casi totalmente el material de base, conservando [sic] sin embargo como sustento del texto, a manera de palimpsesto. (Glantz 2000 cit. en Cote Botero 2014: 129-130)

Las variaciones son: un cambio en los tiempos verbales, un cambio en la perspectiva narrativa, así como algunos cambios estilísticos. Vemos cómo la misma unidad-texto migró de un contexto - una supuesta autobiografía- hacia otro, es decir una supuesta biografía sobre el escritor japonés Mishima. Este desplazamiento es común en la poética de Bellatin: suele inscribir datos de su biografía - o bibliografía- en la biografía de otra persona, o por lo menos cruzarla a partir de comparaciones, superposiciones con su propia autoficción. ${ }^{18}$ Lo vemos tanto en el caso de la Biografía ilustrada-donde el autor aparece incluso en una fotografía, junto a una anciana (fig. 4) - como en el de Las dos Fridas. La presencia del autor-narrador-personaje Mario Bellatin se visibiliza tanto en el universo ficticio creado por la letra como en el creado por la cámara: él es el autor invisible de las fotos, y al mismo tiempo está presente y visible (aunque es la única manifestación donde el autor aparece en las fotos del ciclo 2008-2009).

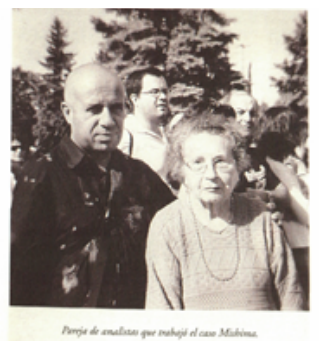

Fig. 4: Pareja de analistas que trabajó el caso Mishima. Biografía ilustrada de Mishima. Edición Alfaguara. (Mario Bellatin

18 Cf. Biografía ilustrada... y "Una cabeza picoteada por los pájaros" (2008/2009). Para un desarrollo pormenorizado de estos conceptos: Carrillo Martín (2010), Vergara (2010), Camenen (2013), Cote Botero (2014). 
$\mathrm{Si}$, para volver a nuestro ejemplo de la tabla 2, la unidad-texto solo está variada, las fotos, en cambio, son diferentes. En "Todos saben que..." se trata de una foto en blanco y negro, donde se ve un compartimento (¿de un tren?) abandonado; ${ }^{19}$ en el caso de Biografía ilustrada vemos una suerte de collage: apoyado en un muro, sobre el pasto, se halla una pintura grande de una casa, sobre un bulto negro en la izquierda de la imagen se ven algunos afiches. La imagen guarda su secreto; no se la puede descifrar completamente, aunque se la mire detenidamente. La foto-Bellatin requiere en la mayoría de las veces de atenta contemplación, no siempre se trata de imágenes fáciles de entender que podrían ser miradas rápidamente; de hecho, se oponen de cierta manera a una "estética de parpadeo" (Courtoisie 2002: 71), contrariamente a la lógica de la escritura de Mario Bellatin que está altamente fragmentada y permite una lectura veloz.

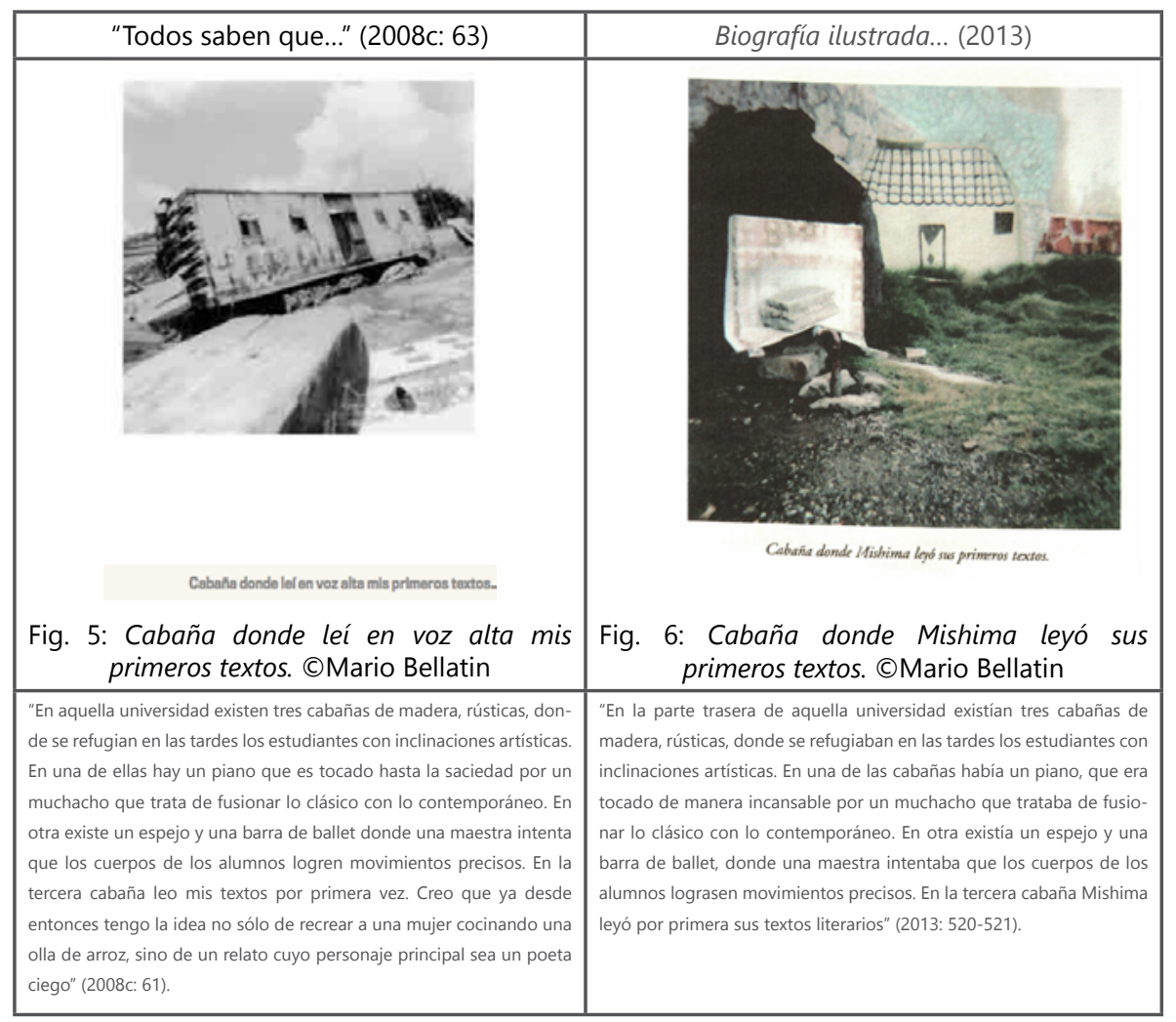

Tabla 2: Misma foto, otra unidad-texto

\footnotetext{
19 Aunque no incluimos al Libro-fantasma en el presente análisis, cabe mencionar que esta foto se volvió a publicar en el Libro-fantasma del Libro uruguayo (2012b: 27).
} 
Las migraciones de las unidades muestran que la creación de un universo no depende, en el sistema Bellatin, de generar siempre nuevos temas (Glantz 2000). Son las variaciones que crean universos a partir de nuevos impulsos asociativos. Los sub-universos están fijados y también limitados por los soporteslibros, pero generan una red de asociaciones en otro espacio, que no es necesariamente físico: el umbral. Ahí, los déjà-vu se confunden con los déjà-lu.

\subsection{La unidad-foto: un núcleo de discursos}

El formato texto-foto-amalgama de Mario Bellatin suscita la creación de redes o rizomas (Deleuze y Guattari 2002), es decir la interconexión de discursos por el medio de la fotografía que se puede ver como nudo que relaciona variaciones, pero también metadiscursos. Las unidades-texto a su vez son variaciones de un tema, como lo demuestra la tabla 3. Seguimos con un ejemplo de una migración entre "Todos saben que..." y la Biografía ilustrada: se trata otra vez de una misma unidad-foto y una variación a nivel de la unidad-texto con los mismos rasgos mencionados para el anterior ejemplo. En el Libro uruguayo encontramos un metadiscurso acerca de las condiciones de la producción de esta foto: se hizo -según las palabras del narrador homodiegético, que nunca es fiable- durante un desfile, se trata de "unas geishas viejas y gordas" (Bellatin 2012a: 43). Asimismo explica qué efectos busca empleando lo borroso en sus fotos: "Esa suerte de efecto hace que no aparezcan en esas fotos más que la presencia del aura de esas mujeres-hombre aparentemente japonesas" (2012a: 43).

Este metadiscurso se publicó cuatro años después de la primera publicación de nuestro ciclo, es decir que es un post-discurso, pero también significa que el ciclo texto-foto-amalgama del 2008-2009 sigue vinculado a la producción más reciente, cuando fomenta el sistema de la auto-referencialidad y de la autocita (Cote Botero 2014: 102). Sin embargo, el autor juega constantemente con la construcción de sentidos en el umbral: al leer y ver solo un texto-foto-amalgama, el lector se confronta con una experiencia intermedial que le va a generar sentimientos individuales (de gusto, de in/comprensión, de imaginación...). En cambio, si el lector lee el metadiscurso, sin saber de la existencia verdadera de dicha foto, se imaginará la imagen a partir de la ékfrasis. El mayor sentido se construye entonces no al considerar únicamente una obra en sí, sino cuando se lee más allá del límite del soporte-libro, es decir en el umbral donde se despliega el sistema rizomático de Bellatin.

Sin embargo se trata solo de un mayor sentido, que nunca es el absoluto. El metadiscurso aporta detalles, explicaciones. Pero también acá son variaciones, de posibles variantes del tema. Así, indica el narrador, después de haber afirmado que se trata en el caso de la publicación de "un texto supuestamente autobiográfico": "Debajo de esa foto debe decir: 'Tías que vinieron del más allá para comprobar el grosor de mi cuello'" (Bellatin 2012a: 44). El pie de foto en "Todos saben que..." (fig. 7) dice en cambio: "Hermanas de mi madre conservando intacta su belleza" (Bellatin 2008c: 63). Lo que se transforma, a su vez, en "Hermanas de la madre de Mishima, quienes de vez en cuando lo van a visitar" (fig. 8 
y 9), aportando de esta manera un detalle más a la unidad-texto de la Biografía ilustrada, donde se omite que sus visitas son ocasionales.

\begin{tabular}{l}
\hline "Todos saben que..." \\
Fig. 7: Hermanas de mi madre conservando intacta su belleza. CMario Bellatin \\
\hline "La felicidad plena, la que creo experimentar cuando recuerdo al perico de mi primo escapando de la jaula, se manifiesta también cuando siento \\
que los objetos pierden conexión con lo real. Esa misma sensación deben haber experimentado las hermanas de mi madre cuando vinieron del \\
más alláy me vieron como a un ser deforme. Pese a estar muertas habían conservado intactas sus bellezas. Hicieron algunas alusiones a mi cuello. \\
A que se había encogido y anchado al mismo tiempo" (2008c: 62).
\end{tabular}

\begin{tabular}{|c|c|c|}
\hline \multicolumn{2}{|c|}{ Biografía ilustrada de Mishima } & El libro uruguayo \\
\hline $\begin{array}{l}\text { Fig. 8: Hermanas de la madre } \\
\text { de Mishima, quienes de vez en } \\
\text { cuando lo van a visitar. Edición } \\
\text { Entropía. CMario Bellatin }\end{array}$ & $\begin{array}{l}\text { Fig. 9: Hermanas de la madre de } \\
\text { Mishima quienes de vez en cuando } \\
\text { lo van a visitar. Edición Alfaguara. } \\
\text { OMario Bellatin }\end{array}$ & $\begin{array}{l}\text { "Yo fui un momento al desfile que se hizo aquí, en una de las ave- } \\
\text { nidas principales. Aparecieron de pronto unas geishas viejas y gor- } \\
\text { das que posaron para mí frente a la catedral. La foto resultante es } \\
\text { borrosa, con el barrido característico de algunas de mis imágenes } \\
\text { [...]. Esa suerte de efecto hace que no aparezcan en esas fotos más } \\
\text { que la presencia del aura de esas mujeres-hombre aparentemente } \\
\text { japonesas" (2012a: 43). } \\
\text { "La imagen salió ahora en la revista Letras Libres junto a un texto } \\
\text { supuestamente autobiográfico. Dice en el pie de foto que ambas } \\
\text { figuras son unas parientes resucitadas que salen de sus tumbas } \\
\text { para apreciar algunos cambios experimentados en mi físico. Sobre } \\
\text { todo en mi cuello que, según las muertas, se ha ensanchado con } \\
\text { el tiempo. [...] [D]eseo ver cómo quedó diagramado el texto con la } \\
\text { imagen. Como te conté, no quiero que ninguno sea independiente } \\
\text { del otro. Debajo de esa foto debe decir: 'Tías que vinieron del más } \\
\text { allá para comprobar el grosor de mi cuello'" (2012a: } 44 \text { ). }\end{array}$ \\
\hline \multicolumn{2}{|c|}{$\begin{array}{l}\text { "La felicidad plena, la que Mishima creyó experimentar cuando recordaba } \\
\text { al perico de su primo escapando de la jaula, se le manifestaba también } \\
\text { cuando era consciente de que los objetos perdían a veces conexión con lo } \\
\text { real. Esa misma sensación debían haber experimentado las hermanas de su } \\
\text { madre, muertas de manera trágica, cuando vinieron del más allá y lo vieron } \\
\text { como a un ser deforme" (2013: 524). }\end{array}$} & \\
\hline
\end{tabular}

Tabla 3: La unidad-foto: un núcleo de discursos

La unidad-foto se puede entender de esta manera como un núcleo de discursos, aunque en el uso intermedial que Mario Bellatin hace de la foto, esta 
tiene más bien la tarea de construir sentidos en el umbral, sean estos un aporte en cuanto a la atmósfera del mundo ficticio, la fortificación del sistema-Bellatin, la construcción de la narración a partir de la imagen, o sellar la escritura, como lo escribe el autor:

Las fotos ocupan casi todo el espacio. Como que sellan la escritura. Terminan de decir lo que la escritura planteó y está imposibilitada, por su carácter mismo de abstracción, de concluir. Le es difícil, por ejemplo, mostrar de un solo golpe lo simultáneo en el tiempo y en el espacio. La relación entre lo vivo y lo muerto. La convivencia de lo falso con lo verdadero. (Bellatin 2012a: 43)

\section{CONCLUSIÓN}

En este ensayo evaluamos las migraciones de las fotografías dentro del sistema bellatinesco del foto-texto-amalgama del ciclo 2008-2009 con las obras Biografía ilustrada de Mishima, Las dos Fridas, Los fantasmas del masajista y del texto "Todos saben que el arroz que cocinamos está muerto. Pequeña autobiografía ilustrada" a partir de las teorías de la intermedialidad provenientes fundamentalmente de modelos germano-hablantes, para considerar una propuesta de constelación literaria en el umbral. En el caso del formato foto-textoamalgama, la intermedialidad induce una doble-lectura diferente a partir de otra materialidad, otro régimen de experimentación del universo ficticio. La relación entre foto y pie de foto es la instancia que genera el enlace hacia el texto verbal. Este sistema se inscribe dentro de una lógica y una materialidad híbrida que no busca instalarse en un centro, sino en el umbral (de materialidades, textualidades, medialidades, géneros y semióticas). El sistema-Bellatin tiene la peregrinación como principio de estructura.

Ahora bien: ¿en qué sentido estas migraciones (o reciclajes) atañen a la construcción de sentido, y de narración? Subrayemos primero que el potencial intermedial reside en un aporte de la otra medialidad. Es un aporte en el sentido de "extra"; en el formato foto-texto-amalgama la foto no es esencial para entender la historia, es más: el texto lingüístico podría ser publicado por sí solo y ofrecer un conjunto narrativo, en cambio las fotos por sí solas resultarían opacas al lector. Con solo mirar las fotos (sin subtítulos) es difícil que haya historia, o narración. En el caso de la obra analizada de Mario Bellatin, este aporte intermedial puede, entre otros, generar:

1. una atmósfera;

2. otra manera en que el texto lingüístico cobra visualidad;

3. más (u otros) detalles que en el texto dados; aquí se instala una "competencia" entre la función de la palabra y la de la imagen;

4. una dimensión lúdica, un lector que se vuelve espectador;

5. una sugerencia de contenido que necesita, gracias a la estética translúcida, ser rellenada por el lector-espectator;

6. una puesta en escena que rompe con el pacto ficcional, así como una distancia hasta irónica. 
En el sistema Bellatin las peregrinaciones hacen evidente que no hay un sentido absoluto, que todo se puede reciclar y generar nuevas experiencias y sentidos. En este ensayo ofrecimos una enumeración y clasificación de los casos donde Mario Bellatin reutilizó una foto en otro contexto de su obra. El sentido de una foto depende de su contexto; las piezas recicladas dentro de la obra se superponen. El lector se instala en una búsqueda permanente de asociaciones, es decir de déjà-vus y déjà-lus. Este proceso se desarrolla en un umbral-el espacio de despliegue del sistema Bellatin- donde se asocian y superponen tanto las migraciones de fotos, las variaciones de textos (temas, motivos), como de metacomentarios, y es ahí donde se construye literalmente otro sentido, una suerte de meta-sentido que deja entrever de manera espectacular la construcción de la obra de Mario Bellatin.

\section{OBRAS CITADAS}

Bellatin, Mario (2002): Shiki Nagaoka: una nariz de ficción. Lima, PUCP / Fondo Editorial. (2003): Perros héroes: tratado sobre el futuro de América Latina visto a través de un hombre inmóvil y sus treinta Pastor Belga Malinois. México D.F., Aguilar. (2006): Jacobo el mutante. Ed. Ximena Berecochea. Buenos Aires, Interzona.

— (2007-2008): "Una cabeza picoteada por los pájaros". En: Otra Parte. Accesible en <http://www.revistaotraparte.com/n\%C2\%BA-13-verano-2007-2008/una-cabezapicoteada-por-los-p\%C3\%A1jaros> [última consulta: 27.01.2015].

(2008a): Demerol: sin fecha de caducidad. México, RM.

- (2008b): Las dos Fridas. México, Consejo nacional para la cultura y las artes / Lumen.

— (2008c): "Todos saben que el arroz que cocinamos está muerto. Pequeña autobiografía ilustrada", Letras Libres, agosto.

- (2009a): Biografía ilustrada de Mishima. Buenos Aires, Entropía.

- (2009b): Los fantasmas del masajista. Buenos Aires, Eterna Cadencia.

- (2011): La clase muerta: dos textos. México D.F., Alfaguara.

- (2012a): El libro uruguayo de los muertos: pequeña muestra del vicio en el que caigo todos los días. Madrid, Sexto Piso.

- (2012b): Libro-fantasma de El libro uruguayo de los muertos. Madrid, Sexto Piso.

_ (2013): Obra reunida. Madrid, Alfaguara.

Bellatin, Mario, y Link, Daniel (2008): "La Nación no gana para sustos", Linkillo (cosas mías), 13 de abril. Accesible en <http://linkillo.blogspot.fr/2008/04/la-nacin-no-ganapara-sustos.html> [última consulta: 02.07.2015].

Böhn, Andreas (ed.) (2003): Formzitat und Intermedialität. St. Ingbert, Röhrig Universitätsverlag.

Camenen, Gersende (2013): “Les étranges texte-images de Mario Bellatin - Fiction biographique et photographie". En: P. Edwards, V. Lavoie y J.-P. Montier (eds.), Photolittérature, littératie visuelle et nouvelles textualités, <http://phlit.org/press/?p=1995> [última consulta: 10.02.2015].

Carrillo Martín, Francisco (2010): "La literatura como performance: Mario Bellatin y Severo Sarduy", Hispamérica, vol. 39, n. ${ }^{\circ} 115$, pp. 37-47. Accesible en <http://www.jstor.org/ stable/25789959> [última consulta: 09.02.2015]. 
Cote Botero, Andrea (2014): Mario Bellatin: el giro hacia el procedimiento y la literatura como proyecto. Pennsylvania, University of Pennsylvania.

Courtoisie, Rafael (2002): "Crisis o vigencia de los géneros narrativos: Literatura transgénica, transgenérica, transmediática". En: Eduardo Becerra (ed.), Desafíos de la ficción. Alicante, Universidad de Alicante / Centro de estudios iberoamericanos Mario Benedetti, pp. 67-76.

Covindassamy, Mandana (2014): W. G. Sebald: cartographie d'une écriture en déplacement. París, PUPS.

Deleuze, Gilles, y Guattari, Felix (2002): Mil Mesetas, capitalismo y esquizofrenia, Valencia, Pre-textos.

Epplin, Craig (2015): "Mario Bellatin: Literature and the Data Imaginary", Revista de Estudios Hispánicos, t. XLIX, n. ${ }^{\circ}$ 1, pp. 65-89.

Genette, Gérard (1972): Figures 3. París, Éditions du Seuil.

Mariniello, Silvestra (2009): "Cambiar la tabla de operación. El medium intermedial", Acta Poetica, vol. 30, n. $^{\circ} 3$.

Mitchell, William John Thomas (1986): Iconology: Image, Text, Ideology. Chicago/Londres, University of Chicago Press.

— (1994): Picture Theory: Essays on Verbal and Visual Representation. Chicago/Londres, University of Chicago Press.

Morris, Adam (2012): "Micrometanarratives and the Politics of the Possible", The New Centennial Review, vol. 11, n. ${ }^{\circ}$ 3, pp. 91-71.

Nünning, Vera, y Nünning, Ansgar (2002): Erzähltheorie transgenerisch, intermedial, interdisziplinär. Trier, WVT Wissenschaftlicher Verlag Trier.

Palaversich, Diana (2003): "Apuntes para una lectura de Mario Bellatin", Chasqui, vol. 32, n. ${ }^{\circ}$, pp. $25-38$.

Rajewsky, Irina O. (2002): Intermedialität. Tubinga/Basilea, A. Francke.

Salinas Escobar, Iván (2006): "Photo et mot: les possibilités narratives de l'image", TRANS-. Revue de littérature générale et comparée. Accesible en <http://trans.revues. org/153> [última consulta: 03.09.2015].

Schmitter, Gianna (2016): "El formato texto-foto amalgama de Mario Bellatin, o la puesta en escena de umbrales". En: Pascale Peyraga, Marion Gautreau, Carmen Peña Ardid Sojo y Kepa Gil (eds.), La imagen translúcida en los mundos hispánicos. Villeurbanne, Orbis Tertius.

Speidel, Klaus (2013): "Can a Single Still Picture Tell a Story? Definitions of Narrative and the Alleged Problem of Time with Single Still Pictures", DIEGESIS, vol. 2, n. ${ }^{\circ}$ 1. Accesible en <https://www.diegesis.uni-wuppertal.de/index.php/diegesis/article/view/128> [última consulta: 21.02.2015].

Vergara, Pablo: "El vacío como gesto: representación y crisis del sentido en la obra de Mario Bellatin". Revista Laboratorio. Accesible en <http://www.revistalaboratorio. cl/2010/05/el-vacio-como-gesto-representacion-y-crisis-del-sentido-en-la-obrade-mario-bellatin/> [última consulta: 09.02.2015].

Wolf, Werner (2002): "Das Problem der Narrativität in Literatur, bildender Kunst und Musik: Ein Beitrag zu einer intermedialen Erzähltheorie". En: Vera Nünning y Ansgar Nünning (eds.), Erzähltheorie transgenerisch, intermedial, interdisziplinär. Trier, WVT Wissenschaftlicher Verlag Trier, pp. 23-104. 